\title{
Relation between Red Blood Cell Distribution Width and Left Ventricular Function In Acute Coronary Syndrome Patients
}

\author{
Khaled Elkhashab $^{(1)}$, Shahira Elshafie ${ }^{(2)}$, Gomaa Abd El Razek ${ }^{(3)}$ and Ahmed \\ Mohammed EL Sakhewy.
}

(1) professor cardiology fayoum university

(2) Professor of clinical and chemical pathology Fayoum University

(3) Lecturer of cardiology Fayoum University

Corresponding author: Ahmed Mohammed EL Sakhewy

E-mail address: ahmedelskhaway@yahoo.com

Tel:01091664778

Fax: +2 084636583

\begin{abstract}
Red blood cells distribution width (RDW) is a measure of red blood cell width variation, reported as part of a standard complete blood count; although it is usually measured, as a routine test, actually its values have been only used in the differential diagnosis of anemia and high values indicate the presence of anisocytosis. It has been demonstrated that RDW could be considered an independent prognostic marker of cardiovascular events in patients with heart failure and peripheral artery diseases. However the role of RDW in patients with acute coronary syndromes (ACS) is less known.
\end{abstract}

Methods: This study included 40 consecutive patients presented with chest pain suggestive of the acute coronary syndrome. Participating subjects were subjected to a detailed history, complete physical examination 12- lead ECG, and routine laboratory investigations including serum cardiac markers and complete blood count including RDW were performed and echocardiography examination including ejection fraction and tissue Doppler.

Results: The study showed statistically significant positive correlation with $\mathrm{p}$-value $<0.05$ between RDW and each of Left atrium, End systolic, and End diastolic dimensions in echo finding which indicates increase in RDW had positive impact on increase of Left atrium, End systolic, and End diastolic, Resting wall motion abnormalities On the other hand there is negative statistically significance correlation with p-value $<0.001$ between RDW and Ejection fraction which indicates increase in RDW had negative impact on Ejection fraction. Also there was significant correlation between RDW and systolic function (s wave of tissue Doppler) with $\mathrm{p}$ value ( $\mathrm{p}$ value $=0.01$ ) Also we found significant correlation between RDW and other parameters age, hypertension, history of ischaemic heart disease. Performing ROC curve analysis between RDW and echocardiography ejection fraction $50 \%$ we found that best cut off point to be $\mathbf{1 6 . 1}$ with sensitivity (79.2\%) and specificity $(62.5 \%)$. Conclusion: Finally our study had lent role of RDW prognostication in acute coronary syndrome patients and opened the door for later investigation exploring the specific behavior of RDW in different patient categories.

KEYWORDS: Red cell distribution width-Acute coronary syndrome-Tissue Doppler. 


\section{INTRODUCTION}

Red blood cells distribution width (RDW) is a measure of red blood cell width variation, reported as part of a standard complete blood count; although it is usually measured, as a routine test, actually its values have been only used in the differential diagnosis of anemia and high values indicate the presence of anisocytosis [Tsuboi S et al, 2013].

RDW is widely available to clinicians because it is routinely reported as part of the complete blood count [Morris M et al, 2001].

Highly significant associations have been described between RDW value and all-cause, noncardiac, and cardiac mortality in patients with coronary artery disease, acute and chronic heart failure, peripheral artery disease, stroke, pulmonary embolism, and pulmonary artery hypertension [Demir A et al, 2002].

It has been demonstrated that RDW could be considered an independent prognostic marker of cardiovascular events in patients with heart failure and peripheral artery diseases

[Nishizaki Y et al, 2012].

Some Authors studied the role or RDW as a predictor of mortality in patients with heart failure [Pascual-Figal DA et al, 2009] others analyzed

between NT-proBNP and RDW in these patients [Holmström A et al, 2012] however the role of RDW in patients with acute coronary syndromes (ACS) is less known and the mechanism by which RDW is related to a poor prognosis in patients with ACS is still unclear [Wang YL et al, 2011]

\section{RDW and cardiovascular disease}

Classical in vitro studies of the function of the coagulation system are performed in plasma, i.e. without erythrocytes or red blood cells (RBCs) [Dahlbäck et al, 2000]

Few studies have therefore investigated the prothrombotic potential of RBCs. However, RBCs are constituents of clots and thrombi formed in vivo [Wohner et al, 2008]
RBCs may play a prothrombotic role in blood coagulation by increasing blood viscosity and forcing platelets towards the vessel wall

[Gersh et al, 2009]

Even small structural differences in RBCs may have a large influence on pathophysiology [Goldsmith et al. 1971]. Moreover, RBCs may actively participate in thrombin generation [Whelihan et al, 2013 ]

\section{Laboratory measurement of RDW}

Modern automated blood cell counters calculate RDW from the RBC volume histogram as an index of heterogeneity [Buttarello et al, 2008]

RDW is often expressed as a percentage coefficient of variation (CV), and is calculated by dividing the standard deviation (SD) of the RBC volume by the MCV [Montagnana et al, 2011] .The result is multiplied by 100 in order to express it as a percentage [Buttarello et al, 2008].

RDW may also be expressed as a direct measurement of the width of the distribution, which gives a measure (in fL) that is independent of mean MCV [Van den Bossche et al, 2002].

The lower reference limit for five different instruments varied between $10.7 \%$ and

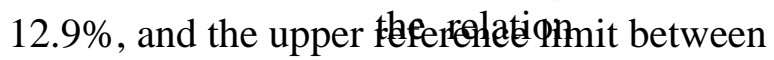
$13.8 \%$ and $15.3 \%$ [Van den Bossche et al, 2002].

At present, any clinical use of RDW must be evaluated by comparison with reference values established for each model of analyser.

\section{Determinants of RDW}

A number of hematological and nonhematological diseases have been associated with increased RDW (Table 1). Increased RDW (i.e. anisocytosis) is common in patients with deficiencies of iron, folate, and vitamin B12 [Briggs et al, 2009].

RDW has been used for differential diagnosis of anemia. RDW is usually normal in 
thalassaemia traits and increased in iron deficiency anaemia. Increased RDW is present in megaloblastic anaemia but RDW is usually normal in macrocytosis due to other causes [Briggs et al, 2009].

However, there is a wide distribution of RDW values within a given disease, which has diminished its usefulness in differential diagnosis. [Briggs et al, 2009].

Increased RDW may be seen in other haematological disorders such as haemolytic anaemia, transfusion, sickle cell/beta thalassaemia, anaemia of chronic disorders, hereditary spherocytosis, and sickle cell anaemia and has also been associated with non-haematological diseases such as chronic hepatobiliary disease, hypothyreosis, hyperthyreosis,

(Dorgalaleh et al, 2013) Behçet's disease, systemic lupus erythematosus and inflammatory bowel disease [Yeşil et al, 2011].

Table 1: Hematological and nonhematological diseases associated with increased red cell distribution width [Bengt Zöller et al, 2014].

\begin{tabular}{|c|c|}
\hline Hematologic disorders & Non-hematological disorders \\
\hline Iron deficiency anemia & Chronic hepatobiliary disease \\
\hline $\begin{array}{l}\text { Megaloblastic anemia (folate and } \\
\text { vitamin B12 deficiency) }\end{array}$ & Hypothyreosis \\
\hline Haemolytic anemia & Hyperthyreosis \\
\hline Sickle cell/beta thalassaemia & Behçet's disease \\
\hline Transfusion & Systemic lupus erythematous \\
\hline Anemia of chronic disorders & Inflammatory bowel disease \\
\hline Hereditary spherocytosis & Peripheral artery disease \\
\hline \multirow[t]{6}{*}{ Sickle cell anemia } & Stroke \\
\hline & Coronary heart disease \\
\hline & Heart failure \\
\hline & Atrial fibrillation \\
\hline & Pulmonary arterial hypertension \\
\hline & Venous thromboembolism \\
\hline
\end{tabular}


Table 2: Laboratory markers and acquired and lifestyle-related factors associated with increased red cell distribution width [Bengt Zöller et al,2014].

\begin{tabular}{|l|l|}
\hline Acquired and lifestyle-related factors & Laboratory markers \\
\hline Age & Inflammatory markers \\
\hline Obesity & Brain natriuretic peptide \\
\hline Low cardiorespiratory fitness & Estimated glomerular filtration rate \\
\hline Smoking & Microalbuminuria \\
\hline High alcohol consumption & Troponin T \\
\hline Being unmarried & Unfavourable lipid profile \\
\hline Obstructive sleep apnoea syndrome & HbA1c \\
\hline Lung function & Short telomere length \\
\hline rs1050828 and rs10493739 variants & \\
\hline
\end{tabular}

RDW was found to be associated with the severity of atherosclerotic disease in patients with PAD [Demirtas et al, 2014] and in a case-control study, increased RDW was associated with ischaemic stroke [RamírezMoreno et al, 2013].

In CAD, TDI-derived systolic velocities have been used as an adjunct to WMSI as a predictor of risk [Marwick TH et al, 2004].

The peak systolic velocity by TDI ( $\left.\mathrm{S}^{\prime}\right)$ is a sensitive marker of mildly impaired LV systolic function, even in those with a normal LVEF or apparently preserved LV systolic function, such as "diastolic HF"[Sanderson JE. et al,2007], or in diabetic subjects without overt heart disease [Fang ZY et al,2004].

\section{Aim of the work}

To evaluate the prognostic implications of red cell distribution width in acute coronary syndrome patient and its relation to left ventricular function (ejection fraction and tissue Doppler) in these patient.

\section{PATIENTS AND METHODS}

This study included 40 patients presented with chest pain suggestive of the acute coronary syndrome admitted to coronary care unit at Fayoum university hospital and Fayoum general hospital

\section{Exclusion criteria}

1. Blood products transfusion in the previous week

2. Medical History of hematological disorders.

3. Recent chemotherapy.

4. Hepatic cirrhosis.

5. Use of drugs known to induce changes in the morphology and rheology of RBC (pentoxyphiline, erythropoietin, cyclosporine) 6. Anemia with hemoglobin less than $7 \mathrm{~g} / \mathrm{dl}$. 
For each patient, a detailed history, complete physical examination 12- lead ECG, and routine laboratory including serum cardiac markers were performed .

According to clinical presentation, ACS was classified into:

1. Unstable angina (UA)

2. Non ST-elevation myocardial infarction (NSTEMI)

3. S-T elevation myocardial infarction (STEMI)

\section{Transthoracic Echocardiographic}

Examination: detailed conventional M-mode and 2-D Transthoracic echocardiographic examination and Doppler study using standard parasternal and apical views following the recommendations by the American Society of Echocardiography (ASE( Measurements of 1. Left ventricular dimensions (LVED dimension and volume and LVES dimension and volume). Volumes were being estimated using Simpson formula.

2. Left ventricular ejection fraction was estimated by $\mathrm{EF}=(\mathrm{EDV}-\mathrm{ESV} / \mathrm{EDV}) \mathrm{X} 100$

3. Wall motion abnormalities The LV was divided according to the 16- segment model as proposed by ASE For each segments, wall motion was identified. Wall motion abnormality was detected if there was hypokinesis, akinesis or dyskinesis.

4. Diastolic function Mitral inflow was assessed by pulsed Doppler with a sample volume between the tips of the mitral leaflets during diastole. The peak early diastolic velocity (E wave), peak atrial velocity (A wave), the E/A ratio, and IVRT were measure.The IVRT was identified as the interval between the aortic valve closure and the mitral valve opening .

Pulsed wave TDI Examination : In each patient, PW-TDI mapping of systolic and diastolic velocities the peak velocities during systole (s wave), and diastole (e and a wave) were measured

RDW calculation: RDW is estimated on fully automated fluorescence flow cytometry 5-part differential analyzer (sysmex xs 800i, Japan) using a sample of EDTA blood which uses the following principle: The XS performs hematology analyses using the following methods: Sheath Flow DC Detection Method, Flow Cytometr y
Methods using a Semiconductor Laser and SLS-hemoglobin method. Blood cells pass through the aperture of the detector surrounded by a sheath fluid using the sheath flow method. The principle of flow cytometry is also used. A semiconductor laser beam is emitted to the blood cells passing through the flow cell. The forward scattered light is received by the photodiode, and the lateral scattered light and lateral fluorescent light are received by the photo multiplier tube. This light is converted into electrical pulses, thus making it possible to obtain blood cell information. Hemoglobin is measured with the SLS-hemoglobin method using Sodium Lauryl Sulfate, which is an analysis method used in previous Sysmex instrumentation.

\section{Statistical Analsis}

$\square$ Data was collected and coded to facilitate data manipulation and double entered into Microsoft Access and data analysis was performed using SPSS software version 18 under windows 7 .

$\square$ Simple descriptive analysis in the form of numbers and percentages for qualitative data, and arithmetic means as central tendency measurement, standard deviations as measure of dispersion for quantitative parametric data, and inferential statistic test:

-For quantitative parametric data:

$\square$ In-depended student t-Test used to compare measures of two independent groups of quantitative data

-Bivariate pearson correlation test to test association between variables

$\square$ The level $\mathrm{P} \leq 0.05$ was considered the cutoff value for significance. 


\section{RESULTS \\ Prognostic yield of red cell distribution width in acute coronary syndrome patients and its correlation with different parameters}

Table(1) illustrates that there is statistically significance positive correlation with p-value $<0.001$ between RDW and age of patients as RDW increase with age. On the other hand RDW shows insignificant correlation with hemoglobin and CK-MB ( $p$ value $=0.7 \& p$ value $=0.4$ respectively)

\begin{tabular}{|l|l|l|l|}
\hline \multirow{2}{*}{ Variable } & \multicolumn{3}{|l|}{ RDW } \\
\cline { 2 - 4 } & $\mathbf{R}$ & p-value & Sig. \\
\hline Age & $\mathbf{0 . 5 7}$ & $\mathbf{6 0 . 0 0 1}$ & HS \\
\hline HB & -0.06 & 0.7 & NS \\
\hline CKMB & 0.13 & 0.4 & NS \\
\hline
\end{tabular}

Table (1): correlation RDW and age, HB and CKMB

There were significant correlation between RDW On the other hand there is no statistically and hypertension, iscaemic heart disease and smoking and insignificant correlation between it and dyslipidemia and diabetes mellitus significant difference with $p$-value $>0.05$ in RDW level between groups of diabetes mellitus, and dyslipidemia groups.

There were insignificant correlation between RDW and ECG findings ( $p$ value=0.2). Also Tropnin showed insignificant correlation with RDW ( $p$ value $=0.3$ ) Also there is statistically significant difference with p-value $<0.05$ between smoking groups as regards to RDW level with low mean among smokers.

there is statistically significant difference with $\mathrm{p}$ value $<0.05$ between RWMA groups with high mean of RDW $(16.1 \pm 2.01)$ among patients who had RWMA 
Table (2): Comparisons of RDW in different history among study group

\begin{tabular}{|c|c|c|c|c|c|}
\hline \multirow{2}{*}{ Variables } & \multicolumn{3}{|l|}{$\begin{array}{l}\text { RD } \\
\text { W }\end{array}$} & \multirow{2}{*}{$\begin{array}{l}\text { p- } \\
\text { valu } \\
\mathrm{e}\end{array}$} & \multirow{2}{*}{ Sig. } \\
\hline & \begin{tabular}{|l} 
No \\
.
\end{tabular} & \begin{tabular}{|l} 
Mea \\
n
\end{tabular} & SD & & \\
\hline \multicolumn{6}{|c|}{ Diabetes mellitus } \\
\hline No & 13 & 15.1 & 2 & \multirow{2}{*}{0.4} & \multirow{2}{*}{ NS } \\
\hline Yes & 17 & 15.6 & 2.4 & & \\
\hline \multicolumn{6}{|c|}{$\begin{array}{l}\text { Hypertensio } \\
\text { n }\end{array}$} \\
\hline No & 15 & 14.4 & 2 & \multirow{2}{*}{0.02} & \multirow{2}{*}{$\mathbf{S}$} \\
\hline Yes & 25 & 16.1 & 2.2 & & \\
\hline \multicolumn{6}{|c|}{$\begin{array}{l}\text { Ischemic Heart disease } \\
\text { (IHD) }\end{array}$} \\
\hline No & 18 & 14.6 & 2.2 & \multirow{2}{*}{0.03} & \multirow{2}{*}{$\mathbf{S}$} \\
\hline Yes & 22 & 15.2 & 2.2 & & \\
\hline \multicolumn{6}{|c|}{ Dyslipidemia } \\
\hline No & 9 & 15.9 & 1.9 & \multirow{2}{*}{0.5} & \multirow{2}{*}{ NS } \\
\hline Yes & 31 & 15.3 & 2.4 & & \\
\hline \multicolumn{6}{|l|}{ Smoking } \\
\hline No & 14 & 16.5 & 2.1 & \multirow{2}{*}{0.03} & \multirow{2}{*}{$\mathbf{S}$} \\
\hline Yes & 26 & 14.9 & 2.2 & & \\
\hline \multicolumn{6}{|l|}{ Troponin } \\
\hline Negative & 7 & 16.2 & $\beta$ & \multirow{2}{*}{0.3} & \multirow{2}{*}{ NS } \\
\hline Positive & 33 & 15.3 & 2.1 & & \\
\hline
\end{tabular}




\section{ECG findings}

Figure (1):

\begin{tabular}{|c|c|c|c|c|c|}
\hline Negative & 1 & 12.4 & b & \multirow{3}{*}{0.2} & \multirow{3}{*}{ NS } \\
\hline & & & & & \\
\hline Positive & 39 & 15.5 & 2.2 & & \\
\hline \multicolumn{6}{|c|}{ RWMA by echo } \\
\hline No & 16 & 14.4 & 2.3 & \multirow{2}{*}{0.02} & \multirow{2}{*}{$\mathbf{S}$} \\
\hline Yes & 24 & 16.1 & 2.01 & & \\
\hline
\end{tabular}

\section{Mean RDW level in different history}

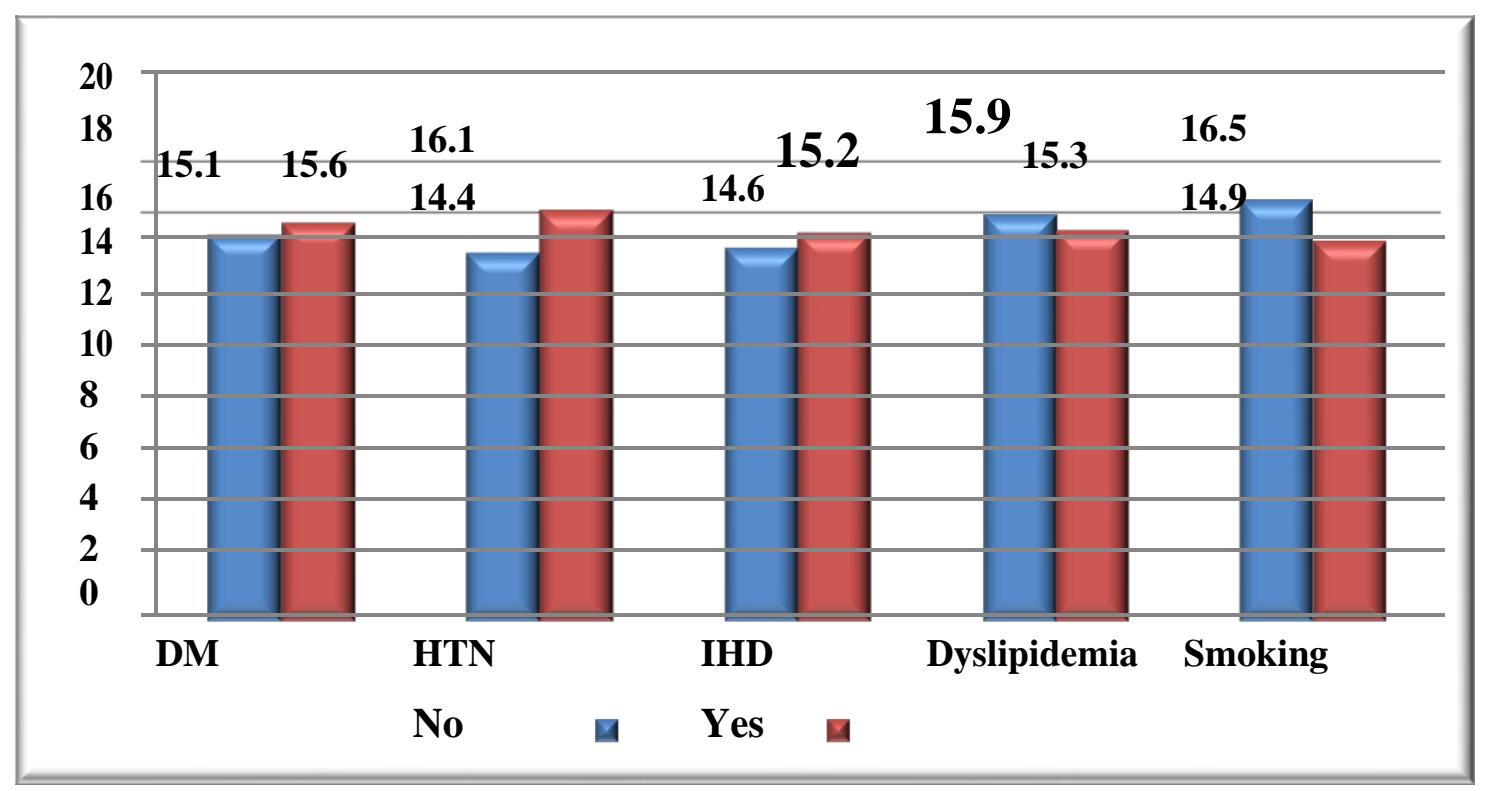

RDW correlation and echocardiography findings and tissue Doppler findings There were significant correlation between left atrium size (LA), end diastolic volume(ED), end systolic volume (ES) and ejection fraction (EF) 
Table (3): Correlation between RDW with Echo-finding among study groups.

\begin{tabular}{|l|l|l|l|}
\hline \multirow{2}{*}{ Echo-finding } & \multicolumn{3}{|l|}{ RDW } \\
\cline { 2 - 4 } & $\mathbf{R}$ & $\mathbf{p}$-value & Sig. \\
\hline LAD & $\mathbf{0 . 3 9}$ & $\mathbf{0 . 0 1}$ & $\mathbf{S}$ \\
\hline EF & $\mathbf{- 0 . 5 6}$ & $\mathbf{0 . 0 0 1}$ & HS \\
\hline ESD & $\mathbf{0 . 4 0}$ & $\mathbf{0 . 0 1}$ & $\mathbf{S}$ \\
\hline EDD & $\mathbf{0 . 3 1}$ & $\mathbf{0 . 0 5}$ & $\mathbf{S}$ \\
\hline S-wave & $\mathbf{- 0 . 3 9}$ & $\mathbf{0 . 0 1}$ & $\mathbf{S}$ \\
\hline E & -0.26 & 0.1 & NS \\
\hline A & 0.05 & 0.7 & NS \\
\hline E/A ratio & -0.02 & 0.9 & NS \\
\hline
\end{tabular}

Table illustrates that there is statistically significance positive correlation with p-value $<0.05$ between RDW and each of LAD, ESD, and EDD level in echo finding which indicates increase in RDW had positive impact on increase of LAD, ESD, and EDD On the other hand there is negative statistically significance correlation with $p$-value $<0.05$ between RDW and EF which indicates increase in RDW had negative impact on EF.

there is statistically significance negative correlation with p-value $<0.05$ between RDW and S-wave in tissue Doppler results which indicates increase in RDW had negative impact on S-wave.

On the other hand there is no statistically significant correlation with $\mathrm{p}$-value $>0.05$ between RDW and any of other tissue Doppler parameters (E, A, and E/A ratio.

\section{Figure (2):correlation between RDW and left atrium}

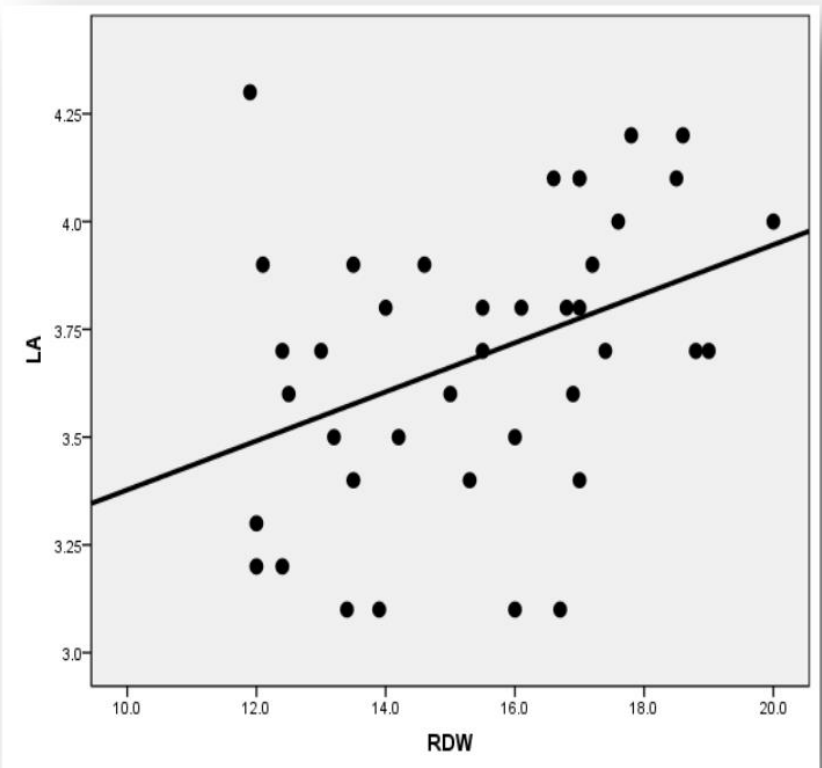




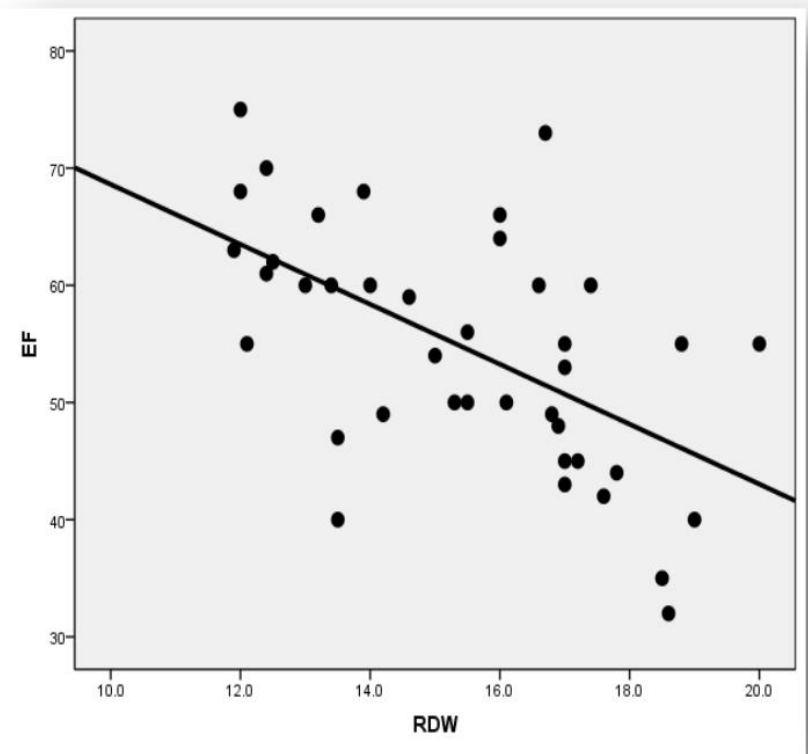

Figure (3): correlation between RDW and ejection fraction

Mean RDW among different RWMA categories

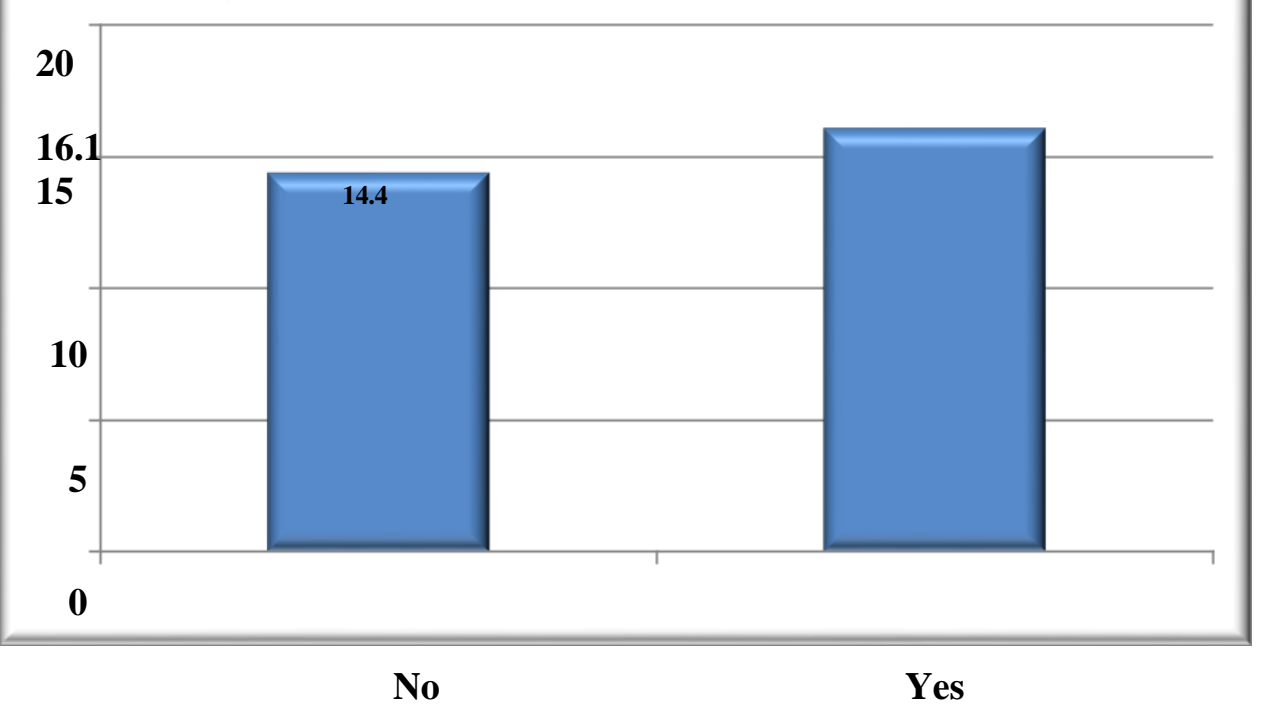

Figure (4): correlation between RWMA and RDW Correlation between RDW and systolic and diastolic function by echocardiography

There was significant correlation between systolic function ( $\mathrm{s}$ wave of tissue Doppler) with $\mathrm{p}$ value ( $\mathrm{p}$ value $<0.01$ ) and there were no significant correlation between RDW and $\mathrm{E}, \mathrm{A}$ and $\mathrm{E} \backslash \mathrm{A}$ ratio 


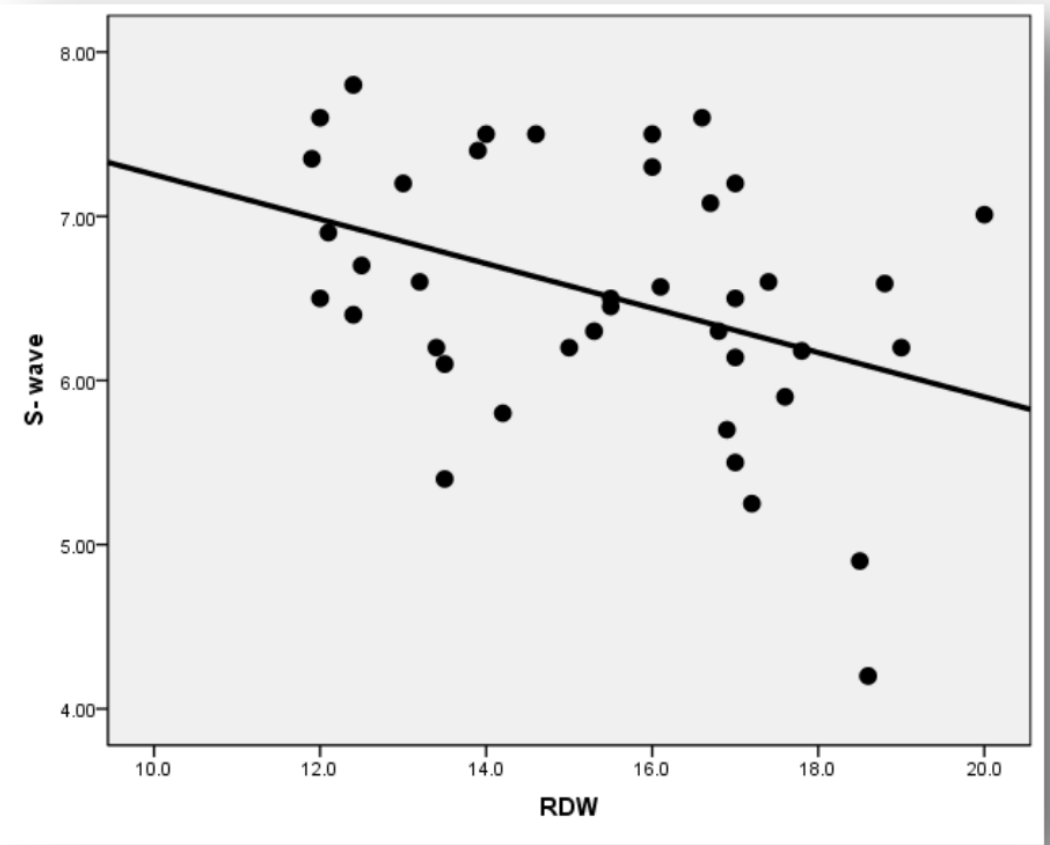

Figure (5): correlation between RDW and s wave tissue doppler

\section{ROC curve for RDW:}

Performing ROC curve analysis between RDW \&echocardiography ejection fraction $50 \%$ we found that best cut off point to be 16.1 with Sensitivity and specificity test for RDW with illustrates probability of being true positive is $(74.9 \%)$ more than being false positive when repeat test 100 times with sensitivity (79.2\%) and specificity (62.5\%)

Table (4): Sensitivity and specificity of RDW in diagnosis of EF \% level among study group.

\begin{tabular}{|l|l|l|l|l|}
\hline Variable & Sensitivity & Specificity & Accuracy & Cut off point \\
\hline RDW & $79.2 \%$ & $62.5 \%$ & $74.9 \%$ & 16.1 \\
\hline
\end{tabular}

Figure (6): ROC curve for RDW

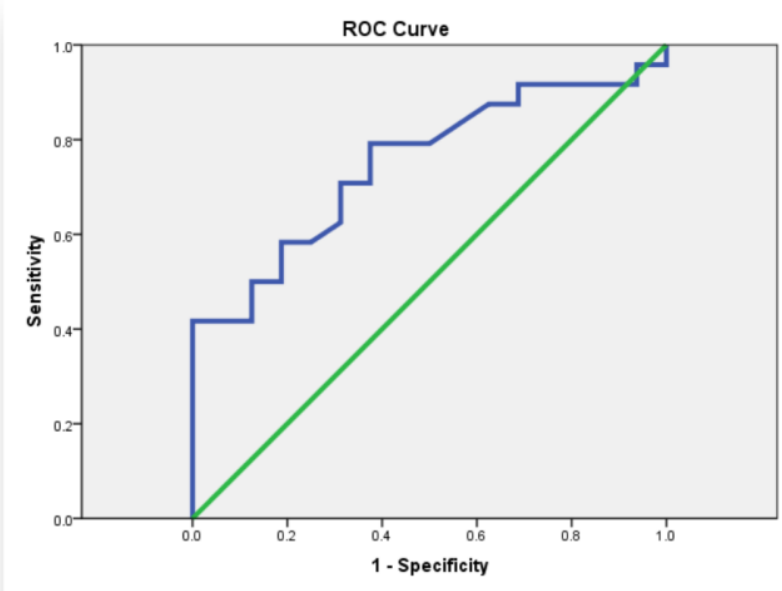

Diagonal segments are produced by ties. 
From all the above we found that RDW has strong correlation with ejection fraction and systolic function by tissue Doppler

\section{DISCUSSION}

Many researchers have demonstrated the role of RDW in patients with heart failure. According to [Al-Najjar et al, 2009] RDW has an independent prognostic power in these patients. They analyzed a cohort of patients with heart failure, comparing RDW with NT proBNP, and they suggested that the two factors can be considered similar in predicting cardiovascular events.

Moreover, the role of RDW as a predictor of mortality in patients with heart failure was investigated. [Pascual-Figal et al, 2009] in patients with acute heart failure higher RDW levels at discharge were associated with worse long-term outcome regardless of hemoglobin levels and anemia status. A role in the prognosis was established also for patients with diastolic heart failure in a study on the relationship between RDW and NT-proBNP [Celik A et al, 2012].

The role of RDW in patients with acute coronary syndrome has not been investigated as well as its role in patients with heart failure.

In this study we evaluated the value of monitoring RDW and its prognostic value and correlation with ejection fraction and pulsed tissue Doppler.

Our study had been conducted over 40 patient diagnosed as acute coronary syndrome.

patients had been enrolled in our study within 24 hours of acute coronary syndrome diagnosis and managed according to standard guidelines of acute coronary syndrome and correlation between RDW and ejection fraction and tissue Doppler was done.

Our patients had mean age $56.4 \pm 9.5$ years, thirty patients $(75 \%)$ were males and 10 patients $(25 \%)$ females our patients had the following presentations:

ST segment elevated myocardial infarction (STEMI) 15 patients (37.5\%), Non ST segment elevation myocardial infarction (Non
STEMI) 14 patients (35\%), and unstable angina 11 patients $(27.5 \%)$.

We investigated the prognostic impact of RDW in acute coronary syndrome and correlate it with echocardiographic findings especially ejection fraction.

Our study revealed a significant negative correlation between RDW and ejection fraction ( $\mathrm{p}$ value $<0.001$ and $\mathrm{r}$ value $=-0.56$ ). this come in context with [yan ling wang et al, 2011] who studied patients with acute coronary syndrome for cardiac mortality and events (heart failure and recurrent infarction within one month) and found that in patients with higher levels of RDW there is lower levels of left ventricular ejection fraction ( $p$ value $<0.001)$.

Also we agreed with [Tadeusz Osadnik et al, 2013] who studied patients with stable coronary disease who underwent PCI and found that with higher RDW values there is lower ejection fraction ( $\mathrm{p}$ value $<0.0001$ ). Also this come in context with [Michael Felker et al, 2007] who studied patients from the North American CHARM (Candesartan in Heart Failure: Assessment of Reduction in Mortality and Morbidity) program with symptomatic heart failure there were strong correlation between ejection fraction and RDW ( $p$ value $<0.0001$ ).

Also our study agreed with [Ali Zorlu et al, 2015] who found that ejection fraction correlated significantly with RDW ( $\mathrm{p}$ value $<0.017$ ).

But our study disagreed with[ Domingo a. pascul-figal et al, 2009] who correlate between RDW and left ventricular ejection fraction (LVEF) and left ventricular diastolic function in acute heart failure patients and found no significant correlation but this difference may be due to different type of patients.

The strong correlation between RDW and ejection fraction suggest RDW as a cheap 
rapid noninvasive prognostic marker that affect patient outcome.

Also our study showed positive correlation between left atrial diameter and RDW (r value $=0.39$ and $p$ value $<0.01)$ this agreed with [Domingo a. pascul-figal et al, 2009] who found that there is positive correlation between left atrial diameter and RDW ( $\mathrm{r}$ value $=0.163$ and $p$ value $<0.006$ ).

Also there was strong significant correlation between age and RDW ( $\mathrm{r}$ value $=0.57$ ) with $\mathrm{p}$ value $<0.001$ this come in context with [Mustafa Çetin et al, 2012] who studied patients with chest pain who underwent coronary angiography and found a positive relationship between and RDW.

Also our study agreed with [feng-lian et al, 2013] who studied patients who underwent coronary angiography due to presence of chest pain and positive treadmill exercise test and RDW is correlated with age.

In our study there was strong positive correlation between s wave which is systolic wave of lateral annulus of mitral valve tissue Doppler and RDW ( $\mathrm{p}$ value $<0.01$ )

In our study there was no significant correlation between RDW and creatinine kinase-MB fraction with ( $\mathrm{p}$ value $=0.4$ ) and This agreed with [Mustafa Duran et al, 2013] who found no correlation between RDW and creatinine kinase-MB fraction insignificant ( $\mathrm{p}$ value $=0.1$ ) and this comes in context with [yan ling wang et al, 2011] who found that no correlation between RDW and creatinine phosphokinase.

In our study we found no significant correlation between troponin level and RDW ( $\mathrm{p}$ value $=0.3$ ) and This agreed with [Erdal Cavusoglu et al, 2009] who studied RDW as predictor of adverse outcome in congestive heart failure with previous history of myocardial infarction and found that correlation between RDW and tropnin and found that it was insignificant $(\mathrm{P}$ value $=0.65)$ and also run parallel to [Mustafa Duran et al, 2013] who found no significant correlation between troponin and RDW.
Both creatinine kinase-MB fraction and troponin are diagnostic markers it is not necessary that they correlate with RDW as it is prognostic.

But in this point our study disagreed with [Ramazan can oncel et al, 2013] Who investigated global registry of acute coronary events (GRACE score) and RDW in ST elevation myocardial infarction patients and found that there is significant correlation between RDW and troponin ( $\mathrm{p}$ value $<0.001) \mathrm{a}$ finding that was not clear in our study as we did not limit patients to ST segment elevation myocardial infarction.

In our study RDW shows insignificant correlation with hemoglobin level ( $\mathrm{r}$ value=0.06 and $p$ value $=0.7$ ).

This comes in context with [Onur Kadir Uysal et al, 2012] who investigated the relation between RDW and STEMI in young patients and found no significant correlation between RDW \&hemoglobin ( $p$ value $=0.5$ ) and with [Savas Sarıkaya et al, 2014] who studied the relation between atrial fibrillation incidence in hypertensive patient and RDW and found that correlation RDW and hemoglobin ( $p$ value $<0.3$ ).

And also agreed with [Feng-lian, et al, 2013] who also found no correlation between RDW and hemoglobin.

Our study discordant with [Michael Felker et al, 2007] who found that correlation between RDW \&hemoglobin significant ( $p$ value $<0.001)$ this may be due to different type of patients as we excluded anemic patients in our study but they did not.

Our study shows insignificant correlation between RDW and diabetes ( $\mathrm{p}$ value $=0.4$ ). This agreed with [Tadeusz Osadnik et al, 2013] who found RDW and diabetes correlation to be insignificant ( $p$ value $=0.2$ ).

Our study shows insignificant correlation between RDW and dyslipidemia ( $\mathrm{p}$ value $=0.5$ ). This agreed with [Onur Kadir Uysal et al, 2012] showed insignificant correlation between hyperlipidemia ( $\mathrm{p}$ value $=0.5$ ). 
Our study shows significant correlation between RDW and hypertension ( $p$ value $<0.02$ ). This agreed with [yan ling wang et al, 2011] who found that there is significant correlation between RDW and hypertension ( $p$ value $<0.001$ ).

Our study shows significant correlation between RDW and history of ischaemic heart disease ( $p$ value 0.03 ). This agreed with [Mustafa Çetin et al, 2012] who found during his study for RDW and its association with coronary atherosclerosis in patient with stable angina that there is significant correlation between RDW and history of ischaemic heart disease ( $p$ value $<0.005$ ).

\section{CONCLUSION}

$\square$ RDW is promising prognostic tool for acute coronary syndrome patients assessment $\square$ RDW on admission can be able to correlate with left ventricular function

\section{REFERENCES}

[1] Tsuboi S, Miyauchi K, Kasai T, et al. Impact of Red Blood Cell Distribution Width on Long-Term Mortality in Diabetic Patient After Percutaneous Coronary Intervention. Circ J 2013; 77(2): 456-61.

[2] Morris M, Davey FR, Henry JB: Basic examination of blood. In Clinical diagnosis and management by laboratory methods. 20th edition.Philadelphia: WB Saunders Company; 2001.

\section{[3] Demir A, Yarali N, Fisgin T, Duru F,} Kara A: Most reliable indices in differentiation between thalassemia trait and iron deficiency anemia. Pediatr Int 2002, 44:612-616.

[4] Nishizaki Y, Yamagami S, Suzuki H, et $\boldsymbol{a l}$. Red blood cell distributionwidth as an effective tool for detecting fatal heart failure in super-elderly patients. Intern Med 2012; 51(17): 2271-6.
Upon attempting to find the best cutoff value of RDW for prediction of left ventricular ejection fraction less than $50 \%$ in acute coronary syndrome partients we found that best cut off point to be 16.1 with sensitivity $79.2 \%$ and specificity $62.5 \%$.

Also this come in cotext with [Ali Zorlu et al, 2015] who found that best cutoff point for diagnosing of severity of ejection fraction less than $45 \%$ is 14 with sensitivity $70 \%$ and specificity $62.5 \%$.

Finally our study suggest a prognostic role of RDW in acute coronary syndrome patients and opened the door for later investigation exploring the specific behavior of RDW in different patient categories.

(ejection fraction and s wave tissue Doppler) in acute coronary syndrome

$\checkmark$ More evaluation of RDW in acute coronary syndrome patients is required

[5] Pascual-Figal DA, Bonaque JC, Redondo B, et al. Red blood cell distribution width predicts long-term outcome regardless of anaemia status in acute heart failure patients. Eur J Heart Fail 2009; 11(9): 840-6.

[6] Holmström A, Sigurjonsdottir R, Hammarsten O, Gustafsson D,Petzold M, Fu ML. Red blood cell distribution width and its relation to cardiac function and biomarkers in a prospective hospital cohort referred for echocardiography. Eur J Intern Med 2012;23(7): 604-9.

\section{[7] Wang YL, Hua Q, Bai CR, Tang Q.}

Relationship between red cell distribution width and short-term outcomes in acute coronary syndrome in a Chinese population. Intern Med 2011; 50(24): 2941 5. Epub 2011 Dec 15.

[8] Dahlbäck B. Blood coagulation. Lancet. 2000; 355(9215):1627-32. 
[9] Wohner N. Role of cellular elements in thrombus formation and dissolution. Cardiovasc Hematol Agents Med Chem. 2008;3(6):224-8.

[10] Gersh KC et al. Fibrin network structure and clot mechanical properties are altered by incorporation of erythrocytes. Thromb Haemost. 2009;102(6):1169-75.

[11] Goldsmith HL. Red cell motions and wall interactions in tube flow. Fed Proc. 1971;30(5):1578-90.

[12] Whelihan MF, Mann KG. The role of the red cell membrane in thrombin generation. Thromb Res. 2013;131(5):377-82.

[13] Buttarello M, Plebani M. Automated blood cell counts: state of the art. Am J Clin Pathol. 2008; 130(1):104-16.

[14] Montagnana $M$ et al. The role of red blood cell distribution width in cardiovascular and thrombotic disorders. Clin Chem Lab Med. 2011;50(4):635-41.

[15] Van den Bossche $\mathbf{J}$ et al. Reference intervals for a complete blood count determined on different automated haematology analysers: Abx Pentra 120 Retic, Coulter Gen-S, Sysmex SE 9500, Abbott Cell Dyn 4000 and Bayer Advia 120. Clin Chem Lab Med. 2002;40(1): 69-73

[16] Briggs C. Quality counts: new parameters in blood cell counting. Int $\mathbf{J}$ Lab Hematol. 2009; 31(3):277-97.

[17] Dorgalaleh A et al. Effect of thyroid dysfunctions on blood cell count and red blood cell indice. Iran J Ped Hematol Oncol. 2013;3(2):73-7.

[18] Yeşil A et al. Red cell distribution width: a novel marker of activity in inflammatory bowel disease. Gut Liver. 2011;5(4):460-7.

[19]Bengt Zölle, Olle Melander, Peter Svensson, Gunnar Engström Red cell distrubution width for predicting cardiovascular disease:A literature review 2014;Doi 2:61-70

[20] Demirtas $\mathbf{S}$ et al. The relationship between complete blood count parameters and Fontaine's Stages in patients with peripheral arterial disease. Vascular. 2014. [Epub ahead of print].

[21] Ramírez-Moreno JM et al. Relation between red blood cell distribution width and ischemic stroke: a case-control study. Int J Stroke. 2013;8(6):E36.

[22] Marwick TH, Case C, Leano R, et al. Use of tissue Doppler imaging to facilitate the prediction of events in patients with abnormal left ventricular function by dobutamine echocardiography. Am J Cardiol 2004;93:142- 6 .

[23] Sanderson JE. Heart failure with a normal ejection fraction. Heart 2007;93:155-8.

\section{[24] Fang ZY, Leano R, Marwick TH.}

Relationship between longitudinal and radial contractility in subclinical diabetic heart disease. Clin Sci (Lond) 2004;106:53- 60 .

[25] Al-Najjar Y, Goode KM, Zhang J, Cleland JG, Clark AL. Red cell distribution width: an inexpensive and powerful prognostic marker in heart failure. Eur J Heart Fail 2009; 11(12): 1155-62.

[26] Celik A, Koc F, Kadi H, et al.

Relationship between red cell distribution width and echocardiographic parameters in patients with diastolic heart failure. Kaohsiung J Med Sci 2012; 28(3): 16572. 
[27] Yan-Ling Wang, Qi Hua, Cheng-Rui

Bai and Qing Tang Relationship between Red Cell Distribution Width and Short-term Outcomes in Acute Coronary Syndrome in a Chinese Population 2011; (DOI: 10.2169).

[28] Tadeusz Osadnik, Joanna Strzelczyk, Michał Hawranek, Andrzej Lekston, Jarosław Wasilewski, Anna Kurek, Aleksander Rafa Gutowski, Krzysztof Wilczek, Krzysztof Dyrbuś, Marek Gierlotka, Andrzej Wiczkowski, Mariusz Gąsior, Andrzej Szafranek and Lech Poloński1 Red cell distribution width is associated with long-term prognosis in patients with stable coronary artery disease 2013, 13:113

[29] Felker GM et al. Red cell distribution width as a novel prognostic marker in heart failure: data from the CHARM Program and the Duke Databank. J Am Coll Cardiol. 2007;50(1):40-7.

[30] G. Michael Felker,Larry A. Allen,Stuart J. Pocock, Linda K. Shaw, John J. V. McMurray,Marc A. Pfeffer ,Karl Swedberg Duolao Wang,Salim Yusuf, vEric L. Michelson, Christopher B. Granger Red Cell Distribution Width as a Novel Prognostic Marker in Heart Failure 2007 doi:10.1016

[31] Ali Zorlu, Hasan Yücel, akki Kaya, Özge Korkmaz, Kutay Yildirimli, Gökhan Bektasoglu Red cell distribution width (RDW) and increased risk of recurrent acute coronary syndrome 2015;Doi 3(2):39-46.

[32] Domingo A. Pascual-Figal*, Juan C. Bonaque, Belen Redondo, Cesar Caro, Sergio Manzano-Fernandez, Jesu's Sa'nchez-Mas, Iris P. Garrido, and Mariano Valdes. Red blood cell distribution width predicts long-term outcome regardless of anaemia status in acute heart failure patients 2009; doi:10.1093.

[33] Mustafa Çetin, Sinan Altın Kocaman, Mehmet Bostan, Aytun Çanga, Yüksel Çiçek, Turan Erdoğan, Ömer Şatıroğlu, Özgür Akgü, Ahmet Temiz, Yavuz Uğurlu. Red Blood Cell Distribution Width (RDW) and its Association with Coronary Atherosclerotic Burden in Patients with Stable Angina Pectoris 2012;Doci 9(1):7-13.

[34] MA Feng-lian, LI Sha, LI Xiao-lin, LIU Jun, QING Ping, GUO Yuan-lin, XU Rui-xia, ZHU Cheng-gang, JIA Yan-jun, LIU Geng, DONG Qian, WU Na-qiong, JIANG Li-xin and LI Jianjun. Correlation of red cell distribution width with the severity of coronary artery disease: a large Chinese cohort study from a single center 2013;Doci 126 (6).

[35] Mustafa Duran, Onur Kadir Uysal,Özgür Günebakmaz, Yücel Yılmaz,Fatih Akın, Oğuzhan Baran,Mehmet Tuğrul İnanç, Namık Kemal Eryol,Ali Ergin, Abdurrahman Oğuzhan, Mehmet Güngör Kaya. Increased red cell distribution width level is associated with absence of coronary collateral vessels in patients with acute coronary syndromes 2013; Doi 10.5543 .

[36] Yan-Ling Wang, Qi Hua, Cheng-Rui Bai and Qing Tang Relationship between Red Cell Distribution Width and Short-term Outcomes in Acute Coronary Syndrome in a Chinese Population 2011; (DOI: 10.2169).

[37] Erdal Cavusoglu Vineet Chopra ,Amit Gupta, Venkata R. Battala, Shyam Poludasu Calvin Eng, Jonathan D. Marmur. Relation between red blood cell distribution width (RDW) and allcause mortality at two years in an unselected population referred for coronary angiography 2009;Doi10.1016. 
[38] Ramazan Can Öncel, Mustafa Uçar, Mustafa Serkan Karakas, Barıs, Akdemir, Atakan Yanıko_glu, Ali Ruza Gülcan, Refik Emre Altekin, Ibrahim Demir Relation of Red Cell Distribution Width (RDW) to GRACE Risk Score To in-Hospital Cardiac Events in Patients with ST-Elevated Myocardial Infarction 2013;Doi62\18\suppl C

[39] Onur Kadir Uysal, Mustafa Duran, Bugra Ozkan, Durmus Yildiray Sahin, Kamuran Tekin, Zafer Elbasan, Fatih Akin, Mehmet Balli, Ozgur Gunebakmaz,Huseyin Arinc, Mehmet Gungor Kaya, Murat Cayli Red cell distribution width is associated with acute myocardial infarction in young patients 2012 ;DOI 10.5603.
[40] Savas Sarıkaya, Șafak Șahin, Lütfi Akyol, Elif Börekçi, Yunus Keser Yılmaz, Fatih Altunkaş, Kayıhan Karaman Is there any relationship between RDW levels and atrial fibrillation in hypertensive patient 2014.

[41] Tadeusz Osadnik, Joanna Strzelczyk, Michał Hawranek, Andrzej Lekston, Jarosław Wasilewski, Anna Kurek, Aleksander Rafa Gutowski, Krzysztof Wilczek, Krzysztof Dyrbuś, Marek Gierlotka, Andrzej Wiczkowski, Mariusz Gąsior, Andrzej Szafranek and Lech Poloński1 Red cell distribution width is associated with long-term prognosis in $\mathrm{p}$ atients with stable coronary artery disease 2013, 13:11 